\title{
Psychological factors related to physical, social, and mental dimensions of the SF-36: a population- based study of middle-aged women and men
}

This article was published in the following Dove Press journal:

Patient Related Outcome Measures

23 October 2010

Number of times this article has been viewed

\author{
Evalill Nilsson' \\ Margareta Kristenson ${ }^{2}$ \\ 'Department of Social and Welfare \\ Studies, Linköping University, \\ Linköping, Sweden; ${ }^{2}$ Department of \\ Medicine and Health, Division of \\ Community Medicine/Social Medicine \\ and Public Health Sciences, Linköping \\ University, Linköping, Sweden
}

Background: Measures of health-related quality of life (HRQoL) are increasingly used as patient-reported outcome measures in routine health care. Research on determinants and correlates of HRQoL has, therefore, grown in importance. Earlier studies have generally been patient-based and few of them have examined differences between women and men. The aim of this study was to explore the relationship between psychological factors and physical, social, and mental dimensions of HRQoL, as measured by the Medical Outcome Study Short Form-36 Health Survey (SF-36), in a normal population and to see if observed relations were the same for women and men.

Methods: Relations between scale scores for the eight scales of SF-36 and scale scores for Self-esteem, Sense of Coherence, Perceived Control, Depressed Mood (CES-D), and Cynicism were assessed through partial correlation and multiple linear regression analyses on a sample of 505 women and 502 men (aged 45-69 years), stratified for sex and adjusted for effects of age, presence of disease, back pain, lifestyle, and social support.

Results: All psychological factors tested, except Cynicism, were significantly correlated to all scales of the SF-36 for women and men (Pearson product-moment partial correlation coefficient, $|r|=0.11-0.63$ and $|r|=0.11-0.60$, respectively). The addition of psychological factors into regression models resulted in significant total explained variance $\left(R^{2}\right)$ changes in all scales of the SF-36 for both sexes. Any discrepancies between women and men pertained more to the strength of relationships rather than the significance of different psychological factors.

Conclusion: In this population-based study, psychological factors showed significant correlation, for women and men alike, with the physical and social scales of SF-36, as well as the mental scales. These findings suggest that assessments of HRQoL are not merely a measure of absolute function but are also dependent on people's perception of their ability.

Keywords: health-related quality of life, patient-reported outcome measures, population

\section{Introduction}

Health-related quality of life (HRQoL) is a concept that attempts to measure those aspects of quality of life that are most directly associated with health, excluding (more indirect) factors such as work and the economy. Although no universally accepted definition of the term exists, most people seem to agree that HRQoL is a multidimensional, self-perceived concept, comprising, at the very least, dimensions of physical, social, and mental well-being and functional ability. Many instruments for measuring HRQoL have been developed over the years. These are either disease-specific or generic, with the latter allowing one to compare different patient groups. One of the most widely used generic instruments is the internationally validated Medical Outcome Study Short Form-36 Health Survey (SF-36). ${ }^{1}$
Correspondence: Evalill Nilsson

Department of Medicine and Health, Division of Community Medicine/Social Medicine and Public Health Sciences, Linköping University, 58। 83 Linköping, Sweden

$\mathrm{Tel}+46$ I0 1037I01

Email evalill.nilsson@liu.se 
The SF-36 and other measures of HRQoL are increasingly used for monitoring the health of populations, and as patientreported outcome measures (PROM) in clinical trials, and following medical treatments in routine health care. ${ }^{2}$ Their use is often part of an explicit goal of focusing on health outcomes so that the needs of people may be served in a more holistic and patient-centered manner. Because these measurements will be used as a basis for decision-making on health policy and medical interventions, it is essential that we continually update and reevaluate what we are thereby measuring. This is even more important as scale scores of the SF-36 has been shown to be capable of predicting future mortality. ${ }^{3-5}$

A considerable number of studies, most of them patientbased, have explored potential determinants and correlates of the SF-36 and other measures of HRQoL. Thus, the impact of sociodemographic factors such as socioeconomic status, ethnicity, marital status, and age on HRQoL is now well established. ${ }^{6}$ Furthermore, the presence of disease has repeatedly been shown to be in an inverse relation with HRQoL ${ }^{7-10}$ but has only been able to explain a part of the variance when used as an explanatory variable in multiple regression analyses. Medical symptoms such as pain are also known to affect HRQoL ${ }^{11,12}$ while firm conclusions regarding the bearing of lifestyle factors (ie, smoking, physical activity, etc) on HRQoL are still in dispute..$^{13-18}$

Several types of psychosocial factors have been suggested as exerting influence on HRQoL. ${ }^{6}$ Psychosocial factors may be divided into extrinsic (ie, social environment, social support) and intrinsic (ie, individual, psychological characteristics). The latter, in turn, can be subdivided into those resources that enhance health and factors associated with increased risk of disease (especially cardiovascular). Such risk factors include negative emotions (eg, anxiety and depression) and cognitions (eg, hopelessness and hostility); examples of resources are coping ability, Sense of Coherence (SOC), and Perceived Control over life. ${ }^{6}$

Many patient-based studies have demonstrated that psychological factors are vital correlates of HRQoL, ${ }^{19-28}$ but there are fewer population studies. ${ }^{29-31}$ Moreover, while earlier studies consistently point to differences in HRQoL levels between women and men, ${ }^{6}$ most of the studies regarding determinants of HRQoL and effects of the psychological factors mentioned above have only adjusted for the effect of sex, and differences between women and men have not been further explored.

Thus, the aim of this study was to explore relations between psychological factors and physical, social, and mental dimensions of HRQoL, as measured by the SF-36, in a normal population and to assess whether observed relations were the same for women and men.

\section{Methods}

\section{Subjects}

Data were collected between October 2003 and May 2004, using random sampling (stratified according to the catchment areas of 10 different primary health care centres, sex and age at 5-year intervals) of the population in the county of Östergötland, Sweden. An invitation letter was sent by post while signing and returning a reply form stated informed consent. Participants were enrolled until the predetermined sample size of 500 women and 500 men between the ages 45 and 69 was obtained. This constituted the basis of the ongoing, prospective Life Conditions, Stress, and Health (LSH) study (see http://www.imh.liu.se/samhallsmedicin/ social medicin/lsh-studien?l=en\&sc=true), with a response rate of $62.5 \%$. The LSH study was designed to investigate whether the relationship between socioeconomic status and coronary heart disease (CHD) is mediated through biopsychosocial pathways. Because the primary outcome is $\mathrm{CHD}$ among participants free of CHD at baseline, the age group 45-69 years was chosen to optimize the number of outcomes after 5-year enrollment in the study. Exclusion criteria were severe physical or mental disease or difficulties in understanding the Swedish language, although exclusion for any of these factors never became necessary. The study sample was representative of the population in terms of educational attainment, immigrant status, and employment rates. Sociodemographic data of the study sample are given in Table 1.

The Ethics Committee of Linköping University, Linköping, Sweden, approved the study.

\section{Procedures}

As part of the protocol of the LSH study, participants (in a fasting state) visited their primary health care centers where anthropometric and blood pressure measurements, in addition to blood, urine, and saliva samples, were obtained. All other data were self-reported by means of questionnaires. At the visit, information about the voluntariness of participating in the study was given verbally. In order to ensure standardization of the data collection, nurses collecting data at the 10 primary health care centers were trained together.

\section{Measures \\ Dependent variable}

The Swedish standard version of SF $-36^{32}$ was used to measure HRQoL. This instrument consists of 36 items, of which 35 
Table I Study sample characteristics including sociodemographic data and scale scores of the SF-36

\begin{tabular}{|c|c|c|}
\hline & Women & Men \\
\hline & \multicolumn{2}{|l|}{ n (\%) } \\
\hline \multicolumn{3}{|l|}{ Age, y } \\
\hline $45-49$ & $99(20)$ & $99(20)$ \\
\hline $50-54$ & $102(20)$ & $10 \mid(20)$ \\
\hline $55-59$ & $10 \mid(20)$ & $104(2 I)$ \\
\hline $60-64$ & $100(20)$ & $99(20)$ \\
\hline $65-69$ & $103(20)$ & $99(20)$ \\
\hline \multicolumn{3}{|l|}{ Education attainment* } \\
\hline $9 y$ & $173(35)$ & $179(36)$ \\
\hline $11 y$ & $165(33)$ & $129(26)$ \\
\hline $12-13 y$ & $50(10)$ & $83(17)$ \\
\hline I4 y (university) & $108(22)$ & $|0|(2 I)$ \\
\hline \multicolumn{3}{|l|}{ Immigrant } \\
\hline Yes & $50(10)$ & $4 \mid(8)$ \\
\hline \multicolumn{3}{|l|}{ Medical conditions } \\
\hline \multicolumn{3}{|l|}{ (presence of disease) } \\
\hline One or more & $302(60)$ & $309(62)$ \\
\hline \multicolumn{3}{|l|}{ Back pain* } \\
\hline Yes & $230(46)$ & $187(37)$ \\
\hline \multicolumn{3}{|l|}{ BMI* } \\
\hline$\leq 19$ & $26(5)$ & $5(1)$ \\
\hline $20-25$ & $197(40)$ & 136 (27) \\
\hline $26-30$ & $170(34)$ & $264(53)$ \\
\hline$\geq 31$ & $105(2 I)$ & $95(19)$ \\
\hline \multicolumn{3}{|l|}{ Smoking } \\
\hline Yes & $92(19)$ & $93(19)$ \\
\hline \multicolumn{3}{|l|}{ Alcohol consumption* } \\
\hline $\begin{array}{l}7 \text { (women)/ I0 (men) or more } \\
\text { glasses/week }\end{array}$ & $39(8)$ & $|3|(26)$ \\
\hline \multicolumn{3}{|l|}{ Physical activity } \\
\hline \multirow[t]{2}{*}{ Less than regularly active } & $378(8 I)$ & $379(82)$ \\
\hline & \multicolumn{2}{|c|}{ Mean $(95 \% \mathrm{Cl})$} \\
\hline \multicolumn{3}{|l|}{ Social support } \\
\hline Social integration & $20(20-2 I)$ & $2 \mathrm{I}(20-2 \mathrm{I})$ \\
\hline Emotional support* & $6(6-6)$ & $5(5-6)$ \\
\hline \multicolumn{3}{|l|}{ SF-36 } \\
\hline $\mathrm{PF}^{*}$ & 80 (79-82) & $87(86-88)$ \\
\hline RP* & $77(74-80)$ & $83(8 I-86)$ \\
\hline BP* & $65(63-68)$ & $72(69-74)$ \\
\hline $\mathrm{GH}^{*}$ & $68(66-70)$ & $72(70-73)$ \\
\hline VT* & $63(6 \mid-65)$ & $69(67-7 I)$ \\
\hline SF* & 85 (83-87) & 90 (88-9I) \\
\hline RE & $84(82-87)$ & $88(85-90)$ \\
\hline $\mathrm{MH}^{*}$ & 77 (75-79) & $81(80-83)$ \\
\hline
\end{tabular}

Notes: *Significant differences between women and men, $P<0.05$.

Abbreviations: $\mathrm{BMI}$, body mass index; $\mathrm{Cl}$, confidence interval; SF-36, Medical Outcome Study Short Form-36 Health Survey; PF, Physical Functioning; RP, RolePhysical; BP, Bodily Pain; GH, General Health; VT, Vitality; SF, Social Functioning; RE, Role-Emotional; $\mathrm{MH}$, Mental Health.

are aggregated into 8 multi-item scales measuring Physical Functioning (PF), Role Physical (RP), Bodily Pain (BP), General Health (GH), Vitality (VT), Social Functioning (SF), Role Emotional (RE), and Mental Health (MH). Items were transformed and aggregated to yield scores from 0 to 100 for each scale, with a higher score indicating a better HRQoL. Factor analyses have shown that PF, RP, and BP constitute the more physically-oriented scales, whereas $\mathrm{MH}, \mathrm{RE}$, and $\mathrm{SF}$ are more psychosocially-oriented. ${ }^{33}$ Two scales, GH and VT, have substantial features of both physical and psychosocial (although GH is usually referred to as a physically-oriented scale and VT as psychosocial).

\section{Independent variables}

\section{Presence of disease and back pain}

Data on the presence of physical disease were self-reported using a checklist. Participants were asked if they had ever been diagnosed by a physician with any of the following 12 medical conditions: myocardial infarction, angina pectoris, stroke, chronic obstructive pulmonary disease, cancer, asthma/allergy, dyspepsia/peptic ulcer, kidney disease, celiac disease, hypertension, hyperlipidemia, or diabetes mellitus. The presence of disease was then defined as at least one of the above medical conditions having been reported. In addition, the presence of musculoskeletal pain in the back of the neck or in the back (henceforth referred to only as back pain) was recorded.

\section{Lifestyle factors}

Smoking habits were categorized as either current smoker (at least 1 cigarette a day) or not. Alcohol consumption was assessed as either drinking $\geq 7 / 10$ (women/men) standard glasses/week or less (one standard glass $=12 \mathrm{~g}$ of alcohol). Questions about alcohol consumption were part of a validated Food Frequency Questionnaire. ${ }^{34}$ Physical activity was measured by questions about daily physical activity (4 levels) and planned physical exercise (5 levels). Responses were then combined into 4 activity levels: regularly active, occasionally active, seldom active, and inactive. ${ }^{35}$ For analytical purposes, this measure was dichotomized as either regularly active or less than regularly active (ie, occasionally/seldom active or inactive). Body mass index (BMI) was used as a measure of weight control and categorized as $\leq 19,20-25,26-30$, or $\geq 31$. Weight and height used for calculating BMI were obtained during visits to the primary health care centers. Although to some extent BMI will measure the same aspects as physical activity, it has also been shown to contribute independently to HRQoL. ${ }^{36}$

\section{Social support}

Social support in terms of the availability of social contacts in the wider social context (social integration) and of close social relationships (emotional support) was measured using validated abbreviated forms of two subscales: availability of 
social integration and availability of attachment both from the Interview Schedule for Social Interaction. ${ }^{37}$

\section{Psychological factors}

The questionnaire included the following five instruments representing psychological resources (higher scores favorable) and risk factors (with lower scores being favorable). (1) Self-esteem ${ }^{38}$ refers to a positive attitude towards oneself, while (2) SOC $^{39}$ reflects to what extent one feels one's own life to be comprehensible, manageable, and meaningful. (3) Perceived Control includes 11 statements adapted from the Whitehall II Study ${ }^{40}$ and the New Barometer studies ${ }^{41,42}$ regarding perceived control over health and perceived control over life. (4) The Center for Epidemiologic Studies Depression scale (CES-D) ${ }^{43}$ was developed in the 1970 s to capture depressed moods in epidemiological studies. (5) Cynicism is one of six subscales from the Hostility Scale, ${ }^{44}$ reflecting a generally negative view of humanity, that depicts others as unworthy, deceitful, and selfish. Psychometric characteristics of the five instruments are given in Table 2.

\section{Statistical analysis}

All analyses were carried out separately for women and men.

Univariate analyses include mean values ( $95 \%$ confidence interval, [CI]) for the psychosocial instruments and the SF-36, and proportions for the variables regarding sociodemographic data, presence of disease, and lifestyle factors. Differences between women and men were assessed using the $z$-test, the Mann-Whitney $U$-test, or the $\chi^{2}$-test.

Correlation analysis using Pearson partial coefficients adjusted for effect of age was carried out to examine the interrelationships between the five psychological instruments. Then, correlation analysis was performed to evaluate the interrelationships between the five psychological instruments and each of the scales of the SF-36 using Spearman and Pearson simple correlation coefficients, as well as Pearson partial coefficients (adjusted for effect of age, presence of disease, back pain, lifestyle, and social support). In order to test the significance of the differences between correlation coefficients in women vs men, the correlation coefficients were converted by means of a $z$-score using Fischer $\mathrm{r}$ - $\mathrm{z}$ transformation.

Multiple linear regression models were used to examine the contribution of the psychological instruments Self-esteem, SOC, Perceived Control, CES-D, and Cynicism, added en bloc, to the total explained variance $\left(R^{2}\right)$ of each of the scales of the SF-36 (the dependent variable), beyond effect of age, presence of disease, back pain, lifestyle, and social support (which were entered, in this order, into the regression model in 5 sequential blocks). Psychological instruments were included en bloc (as the sixth, and last, block) because the intention was to explore the impact of psychology (as a concept) on HRQoL, not to separate the effects of the different instruments.

A significant difference was considered when $P<0.05$. All tests were two-sided.

\section{Results}

Descriptive data regarding the sociodemographic characteristics of the study sample, the presence of disease and back pain, lifestyle, and social support, and scale scores of the SF-36 are given in Table 1. Scale scores of the psychological instruments appear in Table 2. Almost two-thirds of both women and men in the study sample reported at least 1 medical condition, whereas back pain occurred significantly more often among women than men (46\% vs 37\%). More men had BMI $>25$ ( $72 \%$ vs 55\%) than women, and more men had high alcohol consumption ( $26 \%$ vs $8 \%$ ) than women. Regarding the SF-36 and the psychosocial instruments, men generally scored more favorably than women, except with regard to Cynicism and Emotional Support, where women scored more favorably. For both the SF-36 and the psychosocial instruments, parametric and nonparametric tests gave similar results.

The five psychological instruments were low to moderately intercorrelated (Pearson product-moment partial

Table 2 Psychometric characteristics and study sample mean scale scores of the psychological instruments

\begin{tabular}{|c|c|c|c|c|c|c|c|c|c|}
\hline & \multirow{2}{*}{$\begin{array}{l}\text { No. of } \\
\text { questions }\end{array}$} & \multirow{2}{*}{$\begin{array}{l}\text { Score range } \\
\text { (possible) }\end{array}$} & \multirow{2}{*}{$\begin{array}{l}\text { Score range } \\
\text { (in study) }\end{array}$} & \multicolumn{2}{|c|}{ Cronbach $\alpha$} & \multicolumn{2}{|c|}{ Median (IQR) } & \multicolumn{2}{|c|}{ Mean $(95 \% \mathrm{CI})$} \\
\hline & & & & Women & Men & Women & Men & Women & Men \\
\hline Self-esteem & 10 & $10-40$ & $15-40$ & 0.87 & 0.85 & $32(6)$ & $33(6)$ & $32 *(3 I-32)$ & $33 *(32-33)$ \\
\hline SOC & 13 & $|3-9|$ & $32-91$ & 0.83 & 0.81 & $70(16)$ & $70(14)$ & $68(68-69)$ & $69(68-70)$ \\
\hline Perceived control & II & $1 \mathrm{I}-66$ & $27-66$ & 0.71 & 0.66 & $50(\mathrm{II})$ & $52(10)$ & $50 *(49-5 I)$ & $52 *(5 I-52)$ \\
\hline CES-D & 20 & $0-60$ & $0-51$ & 0.69 & 0.64 & $8(9)$ & $6(8)$ & $10 *(9-11)$ & $8 *(7-8)$ \\
\hline Cynicism & 12 & $12-60$ & $12-53$ & 0.86 & 0.84 & $30(\mathrm{II})$ & $33(\mathrm{II})$ & $30 *(29-31)$ & $33 *(32-33)$ \\
\hline
\end{tabular}

Notes: *Significant differences between women and men, $P<0.05$ (tested for mean values only).

Abbreviations: IQR, interquartile range; $\mathrm{Cl}$, confidence interval; SOC, Sense of Coherence; CES-D, Center for Epidemiologic Studies Depression scale. 
correlation coefficient $|r|=0.19-0.63$ [absolute value], adjusting for effect of age; data not shown in tables) and therefore do not seem to measure precisely the same aspects. However, any subsequent multicollinearity between the psychological instruments in the multiple regression analyses was not considered an issue in the present study because we were only interested in the total explained variance.

To explore the relationship between psychology and HRQoL (SF-36), simple and partial (adjusting for effect of age, presence of disease, back pain, lifestyle, and social support) correlation analyses were performed. Most of the correlation coefficients between the psychological instruments and the scales of the SF-36 were significant. Differences between simple and partial correlation coefficients were small, mostly less than 0.05 . The Pearson (parametric) and Spearman (nonparametric) simple correlation coefficients were very similar, with significant $|r|=0.11-0.69$ and $|r|=0.10-0.66$, respectively (simple correlation data not shown in tables).

Partial correlation coefficients are shown in Table 3. Coefficients were generally lower for the physically-oriented SF-36 scales (PF, RP, BP, GH) than the psychosocially-oriented scales (MH, RE, SF, VT). An exception was seen for Cynicism, where correlations with the SF-36 were all nonsignificant, except for a weak correlation $(r=-0.12, P=0.03)$ to PF for men only. Of the five psychological instruments, CES-D generally displayed the highest correlation coefficients.

Except for Cynicism, findings were mainly similar for women and men, but women had significantly greater $r$ values than men $(P<0.05)$ in the following correlations: Self-esteem-VT, Self-esteem-SF, Perceived Control-RE, SOC-RE, and CES-D-SF, ie, for psychosocially-oriented scales of SF-36 and predominantly role-functioning ones.

Finally, multiple linear regression analyses were performed in order to verify the impact of psychological factors on HRQoL, as measured by the SF-36 (see Table 4). For all scales of SF-36, the addition of the 5 psychological instruments en bloc into the regression model resulted in significant $R^{2}$ changes for both women and men (0.02-0.36 for women and $0.05-0.36$ for men). Total $R^{2}$ ranged from 0.26 to 0.56 for women and from 0.17 to 0.47 for men. The lowest explained variance was seen for RP and the highest for MH; this was true for women and men alike. The regression analyses confirmed the results from the partial correlation analyses.

\section{Discussion}

In the present study of a normal, middle-aged population, correlation analyses revealed significant relationships between psychological factors and all scales of the HRQoL

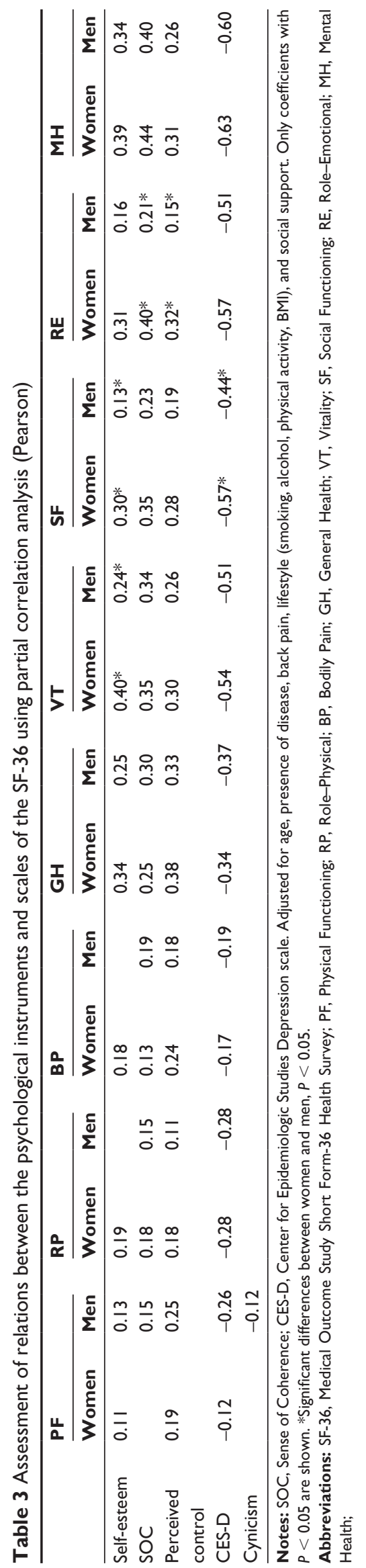




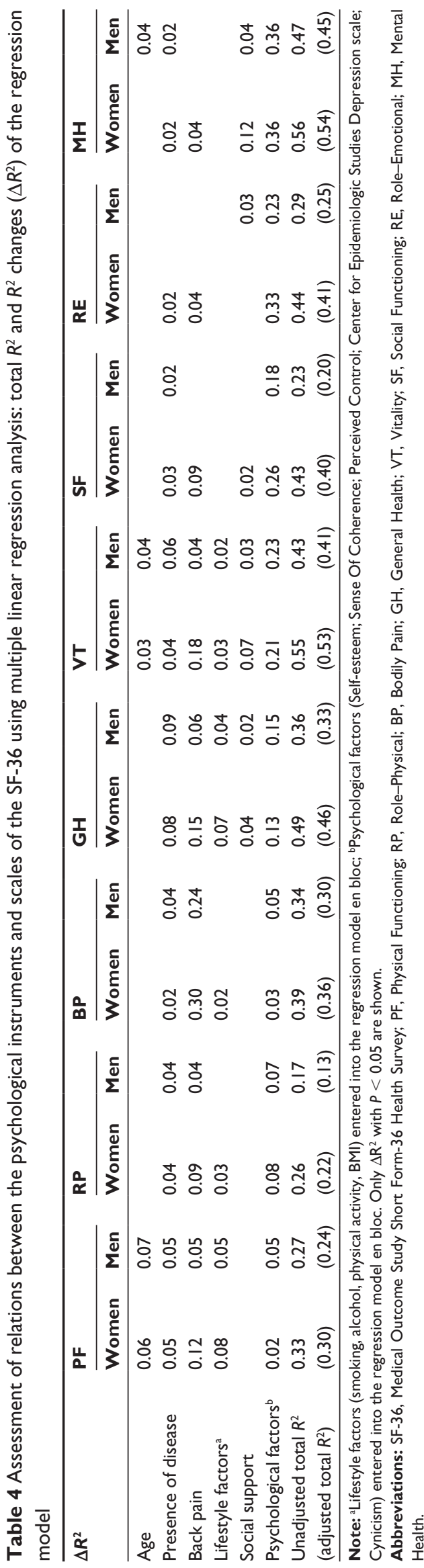

measure (SF-36). In the regression analyses, the impact of psychological factors on HRQoL (SF-36), beyond the effect of presence of disease and lifestyle, was evident. With few exceptions, these results were similar for women and men.

Although a strong relationship between some of the psychological instruments and the mental dimensions of SF-36 was anticipated, the relation between the former and the physical and social dimensions (also noted in earlier studies, eg, Ben-Shlomo et $\mathrm{al}^{26}$ ) suggests that how we perceive our physical and social functioning is not merely dependent on absolute functional ability but on both mood and confidence in ourselves as well.

In the analyses, all psychological instruments were significantly correlated to most scales of the SF-36, except for Cynicism, where a significant correlation was only seen for one scale, PF, and only in the case of men. Although the mean scale scores for Self-esteem, Perceived Control, and CES-D were all more unfavorable among women, men had a more unfavorable mean value for Cynicism, which agrees with earlier studies..$^{45} \mathrm{~A}$ stronger relationship between Cynicism and global self-rated health (the initial question in the SF-36) has been demonstrated for men, ${ }^{45}$ and Cynicism has been found to be a risk factor for future CHD for both men ${ }^{46}$ and women ${ }^{47}$ (which is why Cynicism was included in the present study).

Although psychological factors seem to be important in the evaluation of HRQoL among both women and men, we found sex differences for two scales, SF and RE. Notably, both of these are role-oriented. SF measures "restrictions in social activities due to physical and mental health problems" and RE describes "restrictions in daily activities because of mental health problems". Both of these scales had stronger correlations to measures of "mood" (depression) and "confidence in oneself" (Self-esteem, SOC, and Perceived Control) among women, ie, psychological factors seem to be more important for their perceived social functioning for women compared with men. It has been suggested that women are more "inclusive" than men when making judgments about their global self-rated health; eg, women may have a greater propensity to take into account emotional distress unrelated to their physical well-being. ${ }^{48}$

On the other hand, in a study investigating whether different factors explained global self-rated health in women and men in a normal population, Undén and Elofsson ${ }^{49}$ found that women and men seemed to consider similar factors (including psychological ones, such as self-esteem and depression) when judging their self-rated health, although some sex differences were found in the strength of the 
relationships between psychological factors and self-rated health, in line with our results. Undén and Elofsson concluded that an individual's perspective is probably more important than a gender perspective when trying to improve self-rated health.

The third role-oriented scale, RP, represents restrictions experienced in daily activities due to the respondent's physical condition. This scale showed a large relative increase in explained variance with the addition of psychological factors, especially for men. It is known that psychological factors may lead to avoidance of physical activity, as in kinesiophobia and "fear of movement". ${ }^{50}$ As physical activity is increasingly recognized as a method for both rehabilitation and prevention, and "fear of falling" has in fact been shown to be a key predictor for functional recovery after hip fracture surgery, ${ }^{51}$ above findings may be of importance.

The comorbidity between pain and mental health problems, like depression, is a well-known fact among patients in pain clinics. ${ }^{11}$ We found back pain to be a fairly common phenomenon, explaining the major part of the total variance in the BP scale. Correlation coefficients between psychological factors and the BP scale (which is a combination of the presence of pain and restrictions in daily life due to pain) were not very large; most probably because this study is based on a normal population and where there may be few individuals with considerable psychological factors influencing their pain.

Since our main interest was investigating the importance of intrinsic psychological factors, we only included extrinsic social factors, ie, social support (social integration and emotional support), in the analyses as controls. At first glance, one might find it curious that the social support instruments hardly explained any of the variance in the SF scale (especially in the case of men). However, while the SF scale measures to what extent people feel restricted in their social functioning due to a physical or mental condition (social role functioning), the social support instruments measure the availability of emotional support and social contacts. Thus, personal feelings of social constriction seem to be related more to the perception of one's own ability than actual access to social resources - at least in a population that is neither too old nor too disabled.

Vazquez et $\mathrm{al}^{24}$ has conducted a similarly designed study as ours on hemodialysis patients, in which sociodemographic, clinical, and psychosocial variables (the latter comprising social support, depression, and anxiety) were measured. Lifestyle factors were not considered, and the study was adjusted for the effect of sex. The explained variance increased considerably after the addition of psychosocial variables, as in the case of our results. However, Vazquez et al noted an even greater impact of psychosocial factors on the physically-oriented scales than we did but a smaller effect on the psychosocial scales. For patients afflicted with severe diseases, psychosocial factors play a greater role in their expectations of physical performance, as compared with a normal population. Discrepancies of this sort are important to identify in order to reduce the possible bias of generalizing findings over populations with varying degrees of disability or disease.

Further research is needed to investigate if and how systematic psychosocial interventions, together with medical treatments, will improve patients' HRQoL. For example, patient education designed to enhance the coping abilities among patients with chronic illness and disease, and bearing in mind the possibility of comorbid depression among patients where the anticipated improvement in HRQoL did not occur.

\section{Methodological considerations}

Since this is a cross-sectional study, the direction of causality cannot be determined, but this was not the intention of our study; rather, we aimed at a content analysis to further illuminate the information gained from measures of HRQoL. However, the predictive values of these factors are also important, and since the main design of the LSH study is prospective, we intend to revisit this analysis and look at temporal associations when follow-up data are in place.

The study response rate was $62.5 \%$. It might be suspected that people with lower HRQoL are underrepresented in the study compared with the overall population. For example, in the Whitehall II study of nonindustrial British civil servants, participants with lower baseline SF-36 scale scores or lower socioeconomic status were less likely to participate in followups. ${ }^{52}$ In our case, the study sample was representative of the population as a whole in terms of educational attainment, immigrant status, and employment rates. Furthermore, all socioeconomic groups were represented in the study, as can be seen in Table 1. Bias due to socioeconomic status is, therefore, unlikely. Moreover, even if the present study does contain a selection of people with higher HRQoL, it only strengthens our assumption that psychological factors are also of importance in a seemingly healthy population.

Data on the presence of disease were provided by selfreports, not medical records. However, using a checklist has been shown to be a successful way to increase the accuracy of reporting individual medical conditions. ${ }^{53}$ Since we assessed 
the presence of physical disease on the basis of at least one self-reported condition from our checklist, the problem of recall bias and deliberate withholding of information is presumably small. The latter is primarily noted in the case of mental conditions, ${ }^{53}$ and the former is most likely to be less of a problem: if one has a physical condition that affects one's HRQoL (ie, the kinds of diagnoses of interest in the present study), one is probably more likely to report it. The validity of self-reporting lifestyle factors remains a matter of contention. Regarding alcohol consumption, the relation between self-reports and blood alcohol concentrations found among patients of emergency department in 16 countries was investigated, and in that context, self-reports were determined to be a valid measure of alcohol consumption. ${ }^{54}$

In our study, we have used parametric methods suitable for variables with continuous and normal distributions, although the SF-36 and the psychosocial instruments are known to produce data that have discrete, bounded, and often skewed distributions (although assumed to reflect an underlying continuous conception). However, nonparametric methods showed similar results for all bivariate tests, and linear relationships were further supported by the bivariate scatter diagrams (not shown). Moreover, it has been shown for the SF-36 that in larger studies ( $\mathrm{n}>100)$, multiple linear regression is fairly robust against violations of nonnormality, probably as a result of the central limit theorem. ${ }^{55}$

Although, in one sense, ours was a large study, the number of participants (especially when one stratifies for sex) is not large enough to admit very complicated analyses. Thus, measures of socioeconomic status, eg, were not included. Cross-cultural differences in the relation between the SF-36 and the psychosocial factors also need to be considered.

The fact that total $R^{2}$ was as low as $20 \%$ for some scales of the SF-36 suggests that important explanatory factors are still missing from the analyses. For example, other than back pain, no measures of feeling ill, functional limitations, or other impairments were included, which may at least partially account for the fact that the RP scale had the least explained variance.

The number of analyses performed may lead to a risk of mass significance, such as in the significance tests for differences between women and men. In the present study, all sex differences found with respect to the correlation coefficients were in the same direction, ie, psychological factors were of more importance to women than men, and were found in roughly the same scales of the SF-36, regardless of the psychological factor tested. This implies that differences found are genuine. The general message seems to be that women and men are affected by the same range of psychological factors but may differ in the importance they tend to ascribe to them.

\section{Conclusion}

In this population-based study, psychological factors were significantly related to both the physical and social scales of SF-36, as well as the mental scales, for both women and men. These findings suggest that, in the case of both sexes, measures of HRQoL are not merely an assessment of absolute function but are also conditioned by the way people perceive their own ability. This is important to keep in mind when using HRQoL as PROM in routine health care, especially when the intention is to improve the health for those who score low.

\section{Acknowledgments}

The LSH study is funded by the Swedish Research Council (2004-1881), the Swedish Heart and Lung Foundation (20040530), Linköping University, Sweden, and the County Council of Östergötland, Sweden. We would like to thank statisticians Elisabeth Wilhelm, Nadine Karlsson, and Professor John Carstensen for valuable statistical advice.

\section{Disclosure}

The authors report no conflicts of interest in this work.

\section{References}

1. Ware JE Jr, Sherbourne CD. The MOS 36-item short-form health survey (SF-36). I. Conceptual framework and item selection. Med Care. 1992; 30:473-483.

2. Aaronson NK, Snyder C. Using patient-reported outcomes in clinical practice: proceedings of an International Society of Quality of Life Research conference. Qual Life Res. 2008;17:1295.

3. Sadetsky N, Hubbard A, Carroll PR, et al. Predictive value of serial measurements of quality of life on all-cause mortality in prostate cancer patients: data from CaPSURE (cancer of the prostate strategic urologic research endeavor) database. Qual Life Res. 2009;18: 1019-1027.

4. Otero-Rodriguez A, Leon-Munoz LM, Balboa-Castillo T, et al. Change in health-related quality of life as a predictor of mortality in the older adults. Qual Life Res. 2010;19:15-23.

5. Tsai SY, Chi LY, Lee CH, et al. Health-related quality of life as a predictor of mortality among community-dwelling older persons. Eur J Epidemiol. 2007;22:19-26.

6. Adler N, Marmot M, McEwen B, et al, editors. Socioeconomic Status and Health in Industrial Nations: Social, Psychological and Biological Pathways. New York, NY: New York Academy of Sciences; 1999.

7. Alonso J, Ferrer M, Gandek B, et al. Health-related quality of life associated with chronic conditions in eight countries: results from the International Quality of Life Assessment (IQOLA) Project. Qual Life Res. 2004;13:283-298.

8. Fortin M, Lapointe L, Hudon C, et al. Multimorbidity and quality of life in primary care: a systematic review. Health Qual Life Outcomes. 2004;2:51. 
9. Wee HL, Cheung YB, Li SC, et al. The impact of diabetes mellitus and other chronic medical conditions on health-related Quality of Life: is the whole greater than the sum of its parts? Health Qual Life Outcomes. 2005;3:2.

10. Hopman WM, Harrison MB, Coo H, et al. Associations between chronic disease, age and physical and mental health status. Chronic Dis Can. 2009;29:108-116.

11. Bingefors K, Isacson D. Epidemiology, co-morbidity, and impact on health-related quality of life of self-reported headache and musculoskeletal pain - a gender perspective. Eur J Pain (London, England) 2004;8:435-450.

12. van der Windt DA, Dunn KM, Spies-Dorgelo MN, et al. Impact of physical symptoms on perceived health in the community. J Psychosom Res. 2008;64:265-274.

13. Kimura T, Ogushi Y, Takahashi M, et al. Association of health-related quality of life with health examination including organic functions and lifestyles in Japanese employees. Qual Life Res. 2004;13: 519-529.

14. Strine TW, Okoro CA, Chapman DP, et al. Health-related quality of life and health risk behaviors among smokers. Am J Prev Med. 2005; 28:182-187.

15. Cassidy K, Kotynia-English R, Acres J, et al. Association between lifestyle factors and mental health measures among community-dwelling older women. Aust N Z J Psychiatry. 2004;38:940-947.

16. Kendall AR, Mahue-Giangreco M, Carpenter CL, et al. Influence of exercise activity on quality of life in long-term breast cancer survivors. Qual Life Res. 2005;14:361-371.

17. Renzaho A, Wooden M, Houng B. Associations between body mass index and health-related quality of life among Australian adults. Qual Life Res. 2010;19:515-520.

18. Aoyagi Y, Park H, Park S, et al. Habitual physical activity and healthrelated quality of life in older adults: interactions between the amount and intensity of activity (the Nakanojo Study). Qual Life Res. 2010; 19:333-338.

19. Escalante A, del Rincon I. How much disability in rheumatoid arthritis is explained by rheumatoid arthritis? Arthritis Rheum. 1999;42: 1712-1721.

20. Pearman T. Quality of life and psychosocial adjustment in gynecologic cancer survivors. Health Qual Life Outcomes. 2003;1:33.

21. Carlson LE, Bultz BD. Benefits of psychosocial oncology care: Improved quality of life and medical cost offset. Health Qual Life Outcomes. 2003;1:8.

22. Hart S, Fonareva I, Merluzzi N, et al. Treatment for depression and its relationship to improvement in quality of life and psychological well-being in multiple sclerosis patients. Qual Life Res. 2005;14: $695-703$

23. Tovbin D, Gidron Y, Jean T, et al. Relative importance and interrelations between psychosocial factors and individualized quality of life of hemodialysis patients. Qual Life Res. 2003;12:709-717.

24. Vazquez I, Valderrabano F, Jofre R, et al. Psychosocial factors and quality of life in young hemodialysis patients with low comorbidity. J Nephrol. 2005;16:886-894.

25. Kerr S, Fairbrother G, Crawford M, et al. Patient characteristics and quality of life among a sample of Australian chronic pain clinic attendees. Intern Med J. 2004;34:403-409.

26. Ben-Shlomo Y, Camfield L, Warner T. What are the determinants of quality of life in people with cervical dystonia? J Neurol Neurosurg Psychiatr. 2002;72:608-614.

27. Lev EL, Eller LS, Gejerman G, et al. Quality of life of men treated with brachytherapies for prostate cancer. Health Quality Life Outcomes. 2004;2:28

28. Brink E, Grankvist G, Karlson BW, et al. Health-related quality of life in women and men one year after acute myocardial infarction. Qual Life Res. 2005;14:749-757.

29. Bovier PA, Chamot E, Perneger TV. Perceived stress, internal resources, and social support as determinants of mental health among young adults. Qual Life Res. 2004;13:161-170.
30. Garcia EL, Banegas JR, Perez-Regadera AG, et al. Social network and health-related quality of life in older adults: a population-based study in Spain. Qual Life Res. 2005;14:511-520.

31. Drageset J, Nygaard HA, Eide GE, et al. Sense of coherence as a resource in relation to health-related quality of life among mentally intact nursing home residents - a questionnaire study. Health Qual Life Outcomes. 2008;6:85.

32. Sullivan M, Karlsson J, Ware JE Jr. The Swedish SF-36 Health Survey - I. Evaluation of data quality, scaling assumptions, reliability and construct validity across general populations in Sweden. Soc Sci Med (1982). 1995;41:1349-1358.

33. Ware JE Jr, Gandek B, Kosinski M, et al. The equivalence of SF-36 summary health scores estimated using standard and countryspecific algorithms in 10 countries: results from the IQOLA Project. International Quality of Life Assessment. J Clin Epidemiol. 1998;51: $1167-1170$.

34. Messerer M, Johansson SE, Wolk A. The validity of questionnairebased micronutrient intake estimates is increased by including dietary supplement use in Swedish men. J Nutr. 2004;134:1800-1805.

35. Kallings LV, Leijon M, Hellenius ML, et al. Physical activity on prescription in primary health care: a follow-up of physical activity level and quality of life. Scand J Med Sci Sports. 2008;18:154-161.

36. Kostka T, Bogus K. Independent contribution of overweight/obesity and physical inactivity to lower health-related quality of life in communitydwelling older subjects. Z Gerontol Geriatr. 2007;40:43-51.

37. Unden AL, Orth-Gomer K. Development of a social support instrument for use in population surveys. Soc Sci Med (1982). 1989;29: 1387-1392.

38. Pearlin LI, Schooler C. The structure of coping. J Health Soc Behav. 1978;19:2-21.

39. Antonovsky A. Unraveling the Mystery of Health. San Francisco, CA: Jossey-Bass Publishers; 1987.

40. Marmot MG, Smith GD, Stansfeld S, et al. Health inequalities among British civil servants: the Whitehall II study. Lancet. 1991;337: 1387-1393.

41. Bobak M, Pikhart H, Hertzman C, et al. Socioeconomic factors, perceived control and self-reported health in Russia. A cross-sectional survey. Soc Sci Med (1982). 1998;47:269-279.

42. Bobak M, Pikhart H, Rose R, et al. Socioeconomic factors, material inequalities, and perceived control in self-rated health: cross-sectional data from seven post-communist countries. Soc Sci Med (1982). 2000; 51:1343-1350.

43. Radloff L. The CES-D scale: A self-report depression scale for research in the general population. Appl Psychol Meas. 1977;1(3):385-401.

44. Barefoot JC, Dodge KA, Peterson BL, et al. The Cook-Medley hostility scale: item content and ability to predict survival. Psychosom Med. 1989;51:46-57.

45. Sjögren E. Psychosocial Factors in Adult Life. Linköping, Sweden: Linköping University; 2005.

46. Krantz DS, McCeney MK. Effects of psychological and social factors on organic disease: a critical assessment of research on coronary heart disease. Annu Rev Psychol. 2002;53:341-369.

47. Olson MB, Krantz DS, Kelsey SF, et al. Hostility scores are associated with increased risk of cardiovascular events in women undergoing coronary angiography: a report from the NHLBI-Sponsored WISE Study. Psychosom Med. 2005;67:546-552.

48. Benyamini Y, Leventhal EA, Leventhal H. Gender differences in processing information for making self-assessments of health. Psychosom Med. 2000;62:354-364.

49. Unden AL, Elofsson S. Do different factors explain self-rated health in men and women? Gend Med. 2006;3:295-308.

50. Vlaeyen JW, Kole-Snijders AM, Boeren RG, et al. Fear of movement/ (re)injury in chronic low back pain and its relation to behavioral performance. Pain. 1995;62:363-372.

51. Oude Voshaar RC, Banerjee S, Horan M, et al. Fear of falling more important than pain and depression for functional recovery after surgery for hip fracture in older people. Psychol Med. 2006;36:1635-1645. 
52. Hemingway H, Stafford M, Stansfeld S, et al. Is the SF-36 a valid measure of change in population health? Results from the Whitehall II Study. BMJ (Clinical Research Ed). 1997;315:1273-1279.

53. Knight M, Stewart-Brown S, Fletcher L. Estimating health needs: the impact of a checklist of conditions and quality of life measurement on health information derived from community surveys. J Public Health Med. 2001;23:179-186.
54. Cherpitel CJ, Ye Y, Bond J, et al. Validity of self-reported drinking before injury compared with a physiological measure: cross-national analysis of emergency-department data from 16 countries. J Stud Alcohol Drugs. 2007;68:296-302.

55. Walters SJ, Campbell MJ. The use of bootstrap methods for analysing Health-Related Quality of Life outcomes (particularly the SF-36). Health Qual Life Outcomes. 2004;2:70.

\section{Publish your work in this journal}

Patient Related Outcome Measures is an international, peer-reviewed, open access journal focusing on treatment outcomes specifically relevant to patients. All aspects of patient care are addressed within the journal and practitioners from all disciplines are invited to submit their work as well as healthcare researchers and patient support groups. Areas covered will include: Quality of life scores; Patient satisfaction audits; Treatment outcomes that focus on the patient; Research into improving patient outcomes; Hypotheses of interventions to improve outcomes; Short communications that illustrate improved outcomes; Case reports or series that show an improved patient experience; Patient journey descriptions or research.

\footnotetext{
Submit your manuscript here: http://www.dovepress.com/patient-related-outcome-measures-journal
} 